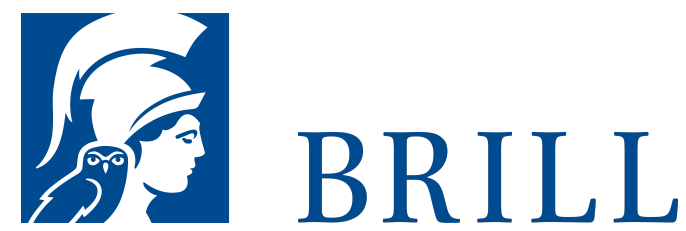

\title{
Prinzipien der Individuation
}

Über das relationale Einzelsein der Lebewesen

Author: Michael Fuchs

Was macht ein Individuum zum Individuum und was kann als Individuum angesehen werden? Diese Fragen beschäftigen die Philosophie seit langem, ohne dass auf sie bisher zufriedenstellende Antworten gegeben worden sind. Gleichzeitig sprechen verschiedene Wissenschaften in unterschiedlichen Zusammenhängen von einer fortschreitenden Individualisierung, so etwa die Soziologie oder auch die Medizin. Die Biologie geht in einigen Forschungszusammenhängen von der Beschreibung individueller Lebewesen über zur Synthese und Konstruktion solcher Wesen. Was also ist es, was hier erzeugt werden soll? Was besagt eine Individualisierung der Medizin oder eine Individualisierung der Gesellschaft? Eine Beantwortung dieser Fragen setzt nicht nur eine philosophische Neubetrachtung der Individualität voraus, sondern auch die Untersuchung der Frage, welche Rolle Individualität im Bereich des Lebendigen spielt. Die hier vorgelegte Studie geht davon aus, dass die Frage nach der Individualität im Allgemeinen und jene nach der Rolle der Lebewesen miteinander verknüpft sind. Lebewesen erweisen sich nicht bloß als ein Anwendungsfall des Individuum-Seins, vielmehr zeigt sich an ihnen exemplarisch, was Individualität ausmacht.

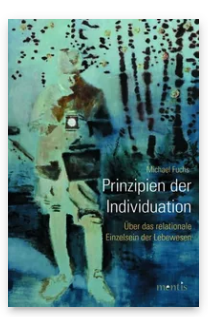

Pages: 418

Seiten

Language:

German

Subjects:

General,

Philosophy

Publisher: Brill | mentis

E-Book (PDF)

Released online: 29 Sep 2015

ISBN: $978-3^{-}$

$95743^{-8}-85^{2-2}$

List price

Paperback

Publication date:

29 Sep 2015

ISBN: 978-3-

95743-037-3

List price 
For more information see brill.com

Order information: Order online at brill.com +44330 333 0049 | customerservices@brill.com Submission information: brill.com/authors

Titles published by Brill | Fink, Brill | mentis or Brill | Schöningh: +49(o)715413279216| brill@brocom.de 